\title{
Trimipramine Maleate
}

National Cancer Institute

\section{Source}

National Cancer Institute. Trimipramine Maleate. NCI Thesaurus. Code C47773.

The maleate salt form of trimipramine, a tricyclic secondary amine of the dibenzazepine class, with an antidepressant property. Trimipramine maleate appears to inhibit serotonin transport and norepinephrine uptake by nerve terminals. This increases available norepinephrine or serotonin and prolongs its action. 